\title{
Sudden Onset of Paraplegia With Rapid Progression to Tetraplegia in a Middle-Aged Man: What is the Diagnosis?
}

Benjamin Ng Han Sim¹*, Tay Shun Qian'1, Wong Sheau Ning ${ }^{2}$

\footnotetext{
${ }^{1}$ Medical Department, Hospital Sibu,

Sibu, Sarawak Malaysia

${ }^{2}$ Radiology Department, Hospital Sibu,

Sibu, Sarawak Malaysia
}

\section{*Corresponding author's email: drben84@gmail.com}

Received: 1 April 2021

Accepted: 13 September 2021

DOI: https://doi.org/10.51200/bjms.vi.3141

\section{QUESTION}

A 58-year-old man, known case of diabetes mellitus, hypertension presented with sudden onset of bilateral lower limb weakness while resting, to the nearby medical centre. The weakness later progressed to involve bilateral upper limbs, leaving him tetraplegic, 3 hours from symptom onset. He denied chest or back pain. His electrocardiogram (ECG) revealed sinus rhythm, without any acute ischemic changes. There was no preceding febrile illness or injury. His case was referred to our centre with the impression of Guillain-Barre Syndrome (GBS).

He came to us, about 12 hours after the onset of weakness. Initial assessment revealed a flaccid tetraplegia man with modified medical council (MMC) power of 0/5 for all 4 limbs and generalised areflexia. Sensory modalities: pinprick and proprioception, were otherwise intact. His vital signs revealed blood pressure ranges of $100-106 / 60-70 \mathrm{mmHg}$, with bradycardia (heart rate of $55-60$ beats/ min), afebrile with good oxygenation under room air. There was a loss of bulbo-cavernous reflexes, anal tone, and perianal sensation. $\mathrm{He}$ had urinary retention. These constellations of signs were consistent with spinal shock.

The cerebrospinal fluid (CSF) analysis revealed mildly raised protein of $0.66 \mathrm{~g} / \mathrm{l}$, with a cell count of one/mm3, CSF to serum glucose ratio of more than 0.6 , and negative for microbiology analysis. 
Magnetic resonance imaging (MRI) of his spine is shown in Figures 1 and 2.

Interpret the findings and suggest the provisional diagnosis.

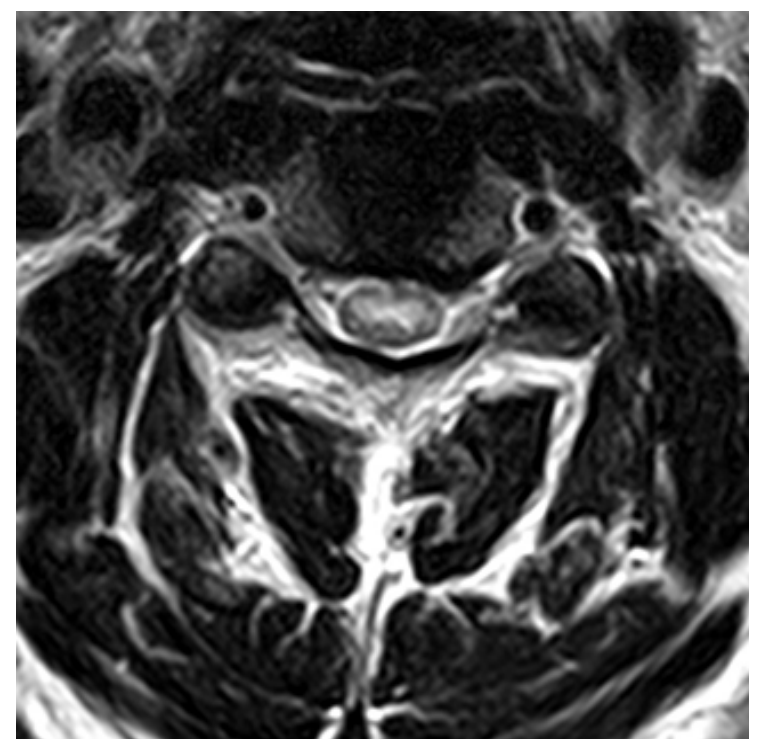

Figure 1 Axial T2WI MRI (magnified view) at the cervical cord level

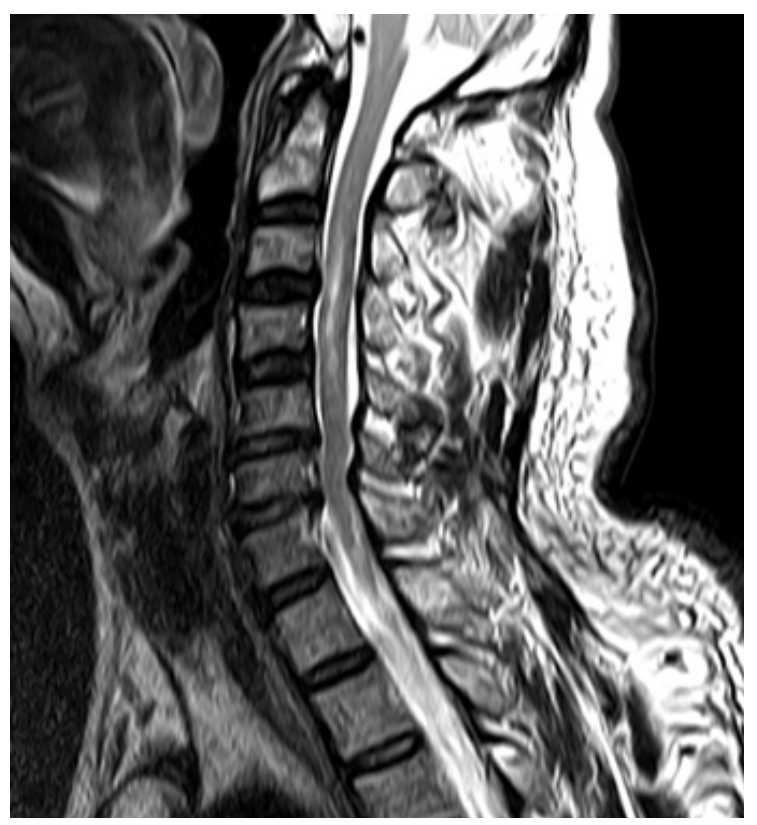

Figure 2 Sagittal T2WI MRI Cervical cord

Please find out the answer in the next issue.

\section{CONFLICT OF INTEREST}

The authors declare that they have no competing interests in publishing this article.

\section{CONSENTS}

Written consent was obtained from the patients to publish the article (including images, case history, and data). A copy of the written consent is available for review by the Chief Editor.

\section{ACKNOWLEDGMENTS}

The authors would like to thank the Neuroradiology team of Kuala Lumpur Hospital for their expert input on the neuroimaging in this case.

\section{REFERENCES}

Diehn, F. E., \& Krecke, K. N. (2021). Neuroimaging of Spinal Cord and Cauda Equina Disorders. Continuum (Minneapolis, Minn.), 27 (1), 225 - 263. https://doi.org/10.1212/ CON.0000000000000926

Romi, S., \& Naess, H. (2016). Spinal cord infarction in clinical neurology: A review of characteristics and long-term prognosis in comparison to cerebral infarction. Eur Neurol, 76 (3 - 4), 9598. https://doi.org/10.1159/000446700

Saber, M., \& Gaillard, F. (2021). Acute spinal cord ischemia syndrome. Radiopaedia. https:// radiopaedia.org/articles/acute-spinalcord-ischaemia-syndrome, https://doi. org/10.53347/rlD-93820 